\title{
Design and Manufacture on Newly Developed Rotary and Building Ridge Combined Work Machine
}

\author{
Liping Zhao ${ }^{1, \mathrm{a}}$, Xinru He ${ }^{1, \mathrm{~b}}$,Xiangyu Meng ${ }^{1}$
}

${ }^{1}$ Jilin Agricultural University, the College of Engineering and Technology, China, Jilin Changchun 130118

a245042057@qq.com, ${ }^{\mathrm{b}} 1113675647 @ q q . c o m$

Keywords: rotary, building ridge, a multi-function machine, design, combined work

Abstract: In this paper, a kind of rotary and building ridge combined work machine was designed and manufactured on a rice paddy production. The tractor was used and land rotary tillage and ridging were completed at the same time. It mainly consists of the traction frame, machine frame, gearing parts, rotary parts, set shovel soil, building ridge squeezing parts, cylinder. Field tests have showed that the structure was designed reasonably and the supports were provided to mechanization of rotary and ridging combined work in paddy field.

\section{Introduction}

Rice is the main food crop in China, and because it has the characteristic of high yield, it plays a very important role in food production ${ }^{[1]}$. Building ridge is the soil preparation of rice mechanized production. As shown in literatures ${ }^{[2-10]}$, building ridge relies on manpower to complete and manual building ridge is an arduous and expensive work of labor.Even with the help of some special tools, its labor intensity is still great, work efficiency being very low, cost being very high, ridge of the consistency and uniformity is poor, which needs assisting compaction by manpower. Manual building ridge is not suitable for China plain area rice cultivation, which also goes against the development of rice mechanized production.

For this reason, a new rotary and building ridge combined work machine is designed in this paper. The machine can be directly attached to $70 \sim 90 \mathrm{~kW}$ wheeled tractor, which can complete tillage and at the same time building a ridge. The machine has the advantages of high efficiency, low cost, good effect of plowing and building ridge, which has important practical significance to paddy field mechanization and provides technical support and guarantee for rice production.

\section{Structure and working principle}

Structure of the combined working machine is shown in Figure.1.

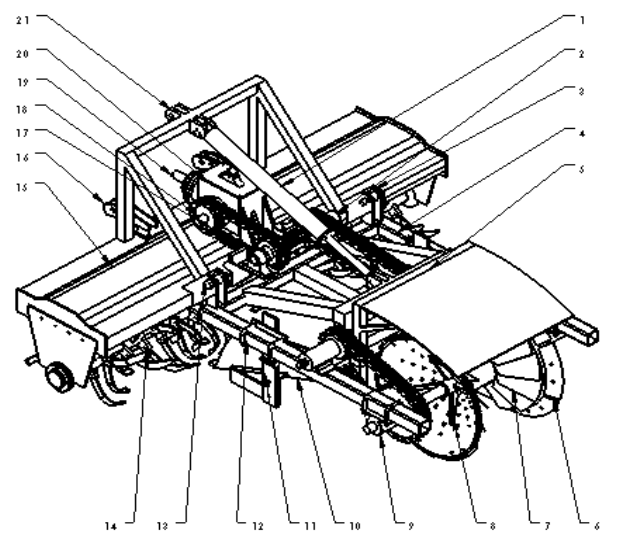

1. hydraulic cylinder 2 . bearing box of axis III 3. connecting pin 4.frame of set soil and building ridge 5 . baffle of building ridge mechanism 6. repression blade 7. elastic blade 8. pressing and molding roller 9. bearing box of pressing and molding roller 10. set soil shovel 11.upright column of soil shovel 12. pedestal of soil shovel 13. bearing box of axis 14. assembly of rotary blade 15 . retaining board of rotary machine 16.traction frame 17. chain wheel I 18.axis II 19.axis I 20.gear box 21.rotary frame

Figure.1 Structure of the rotary and building ridge combined work machine

As shown in figure.1, the machine consists of traction frame, machine frame, rotary pulverizing 
parts, clutch, set shovel soil, pressing and molding roller, hydraulic lifting mechanism and other components. The working principles of machine are showed as follows: the power is transmitted to the gearbox 20 by the cardan joint, and then the power is transmitted through the output shaft to pushing and molding roller 8 by a pair of bevel gears; meanwhile, spur-gear is installed with the bevel gear on the same axis and the power is transmitted to assembly of rotary blades through four spur gear drive, then forming a relatively complete mechanical transmission system. The power is transmitted to cutter shaft by gearbox 20, and then both cutter shafts rotate in order to achieve the effect of soil tillage. The soil shattered by rotary blades is collected by the soil shovel, and then becomes a soil ridge preliminary. And then, soil ridge is pressed by pressing and molding roller, forming a hard, smooth soil ridge.

\section{Design of main working parts}

\section{Design of the transmission system}

Structure of the transmission system is shown in Figure.2. When working, the output power of the tractor is transmitted to the transmission input shaft of the gearbox through the cardan joint, and then axis II rotates through the engagement of a pair of bevel gears on the input axis I. Power of axis II is transmitted to the axis III, axis IV, both half rotary blade shaft rotate to complete the rotary tillage; on the other hand, power of axis II is transmitted to axis V, axis VI by the chain wheel of axis II, then pressing and molding roller rotates and soil is molded.

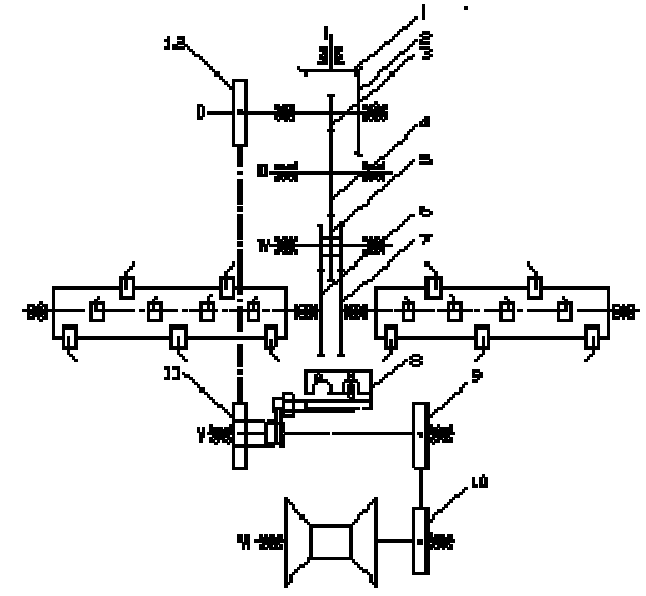

Figure.2 Structure of the transmission system

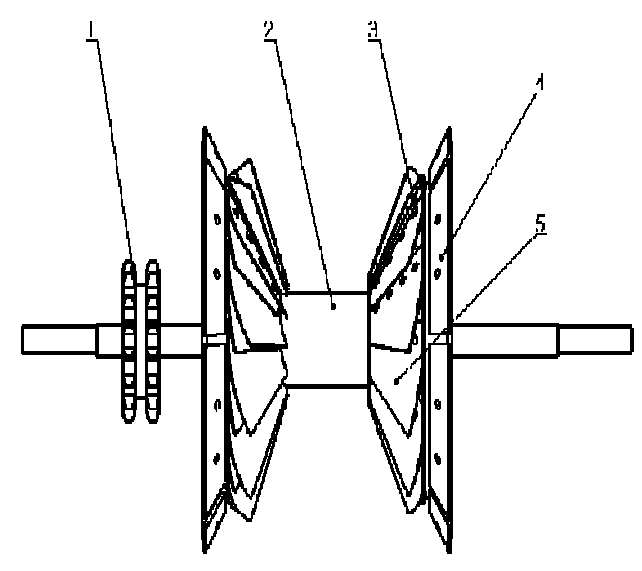

1. chain wheel VI 2. pressing and molding roller 3. bolt hole 4. plastic tablet 5. elastic tablet

Figure.3 Structure of push forming roller

\section{Design of lifting parts}

Lifting device is designed on this machine in order to achieve two functions. As shown in Figure 1, rotary frame 21 and building ridge frame 4 is connected by the hydraulic cylinders. Hydraulic cylinders can be extended or indented, using a tractor as the driving force. When the hydraulic cylinder extending, the ridging parts are lifted on the ground and the machine can achieve rotary and building ridge combined work; When there is no need to build ridge, building ridge parts can rotate 90 degrees around axis $\mathrm{V}$ to achieve lifting by indenting the hydraulic cylinder, which achieving the adjustable type of double functions and convenient transportation operation.

\section{Design of soil collecting device}

In order to build a smooth ridge at the same time of soil preparation, enough soil must be collected in the place of building ridge. A pair of soil shovels with semi spiral plough surface are used as the set soil mechanism of the machine, which has the advantages of simple structure, easily assembled, lifting 
flexibly, easy to control deep tillage. Besides, it has strong ability of plowing, which is suitable for burying weeds,straw, residues. As shown in figure 1, it mainly consists of soil shovel 10, upright column 11, pedestal of soil shovel 12,etc. Soil shovels and upright columns are connected with bolts, upright columns fixed in pedestal of soil shovel using $U$ type bolts and pedestal of soil shovel 12 and building ridge frame 4 is fixedly connected.

To ensure the collection of soil shovel meeting soil requirement of building ridge, set shovel soil column and pedestal of soil shovel are adjustably connected, which can be adjusted up and down and makes different buried depth. When set shovel soil column down, shovel tip buries deep, setting large amount of soil, otherwise setting small amount of soil which can achieve changing soil volume and build ridge as the required size of field.

Due to the set shovel soil bearing lager radial force and axial force and bearing more load force than rotary cutter shaft, material is chosen as $65 \mathrm{Mn}$ steel and hardness requirements of heat treatment is $\mathrm{HRC} 45 \sim 50$.

\section{Design of pressing and molding device}

The design of the ridging parts is rotatable, mounted behind the set shovel soil. The section of the building ridge is trapezoid and the ridge should have a certain degree of soil compaction. Pressing and molding device consists of pressing and molding roller, left conical wheel hub and right conical wheel hub, which was designed as the shape of the building ridge. Both sides of conical wheel hub consist of elastic tablet and plastic tablet which was connected by bolts. Structure of push forming roller is shown in Fig.3

When the machine operated jointly, the pressing forming roller rotates away from the soil, the elastic tablet 5 returning to original shape; When the pressing forming roller rotates into the soil, elastic tablet 5 shrinks towards both sides of the conical hub surface due to the force from both sides of the ridge, achieving pressing and patting of the ridge. Thus, the surface of the building ridge is smooth and strong and the quality is very good. Changing the size of elastic tablet plastic tablet, pressing and molding roller, it can change the width and height of the building ridge to meet different size requirements of different areas. The section of the building ridge is trapezoid, whose height, top width and the bottom width are $300 \mathrm{~mm}, 300 \mathrm{~mm}$ and $650 \mathrm{~mm}$, respectively.

\section{Manufacture of newly developed rotary and building ridge combined work machine}

A photo of the rotary and building ridge combined work machine is shown in Fig.4. Picture of operating result is shown in Fig.5.

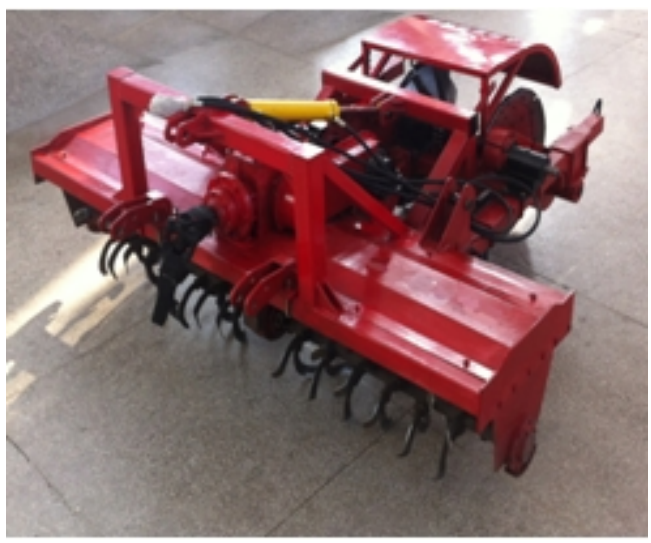

Figure.4 A photo of the rotary and building ridge combined work machine

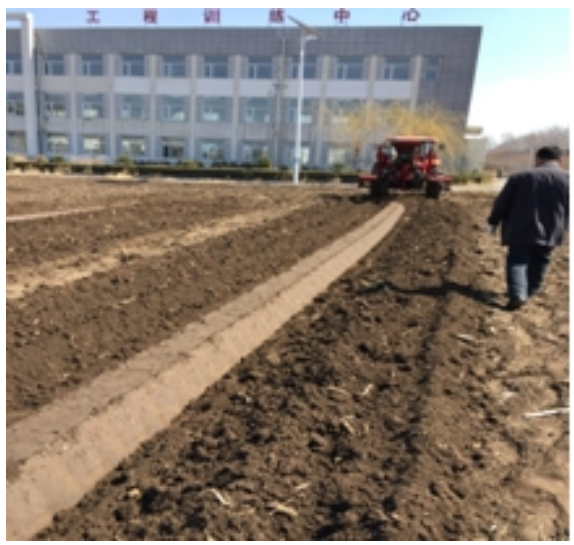

Figure.5 Picture of operating result 


\section{Conclusion}

A newly rotary and building ridge machine was designed in this paper,including transmission system, lifting parts,soil collecting device,pressing and molding device and the machine was manufactured by engineering training center of Jilin Agricultural University. As known from the field experiment: The auxiliary power is $70 \sim 90 \mathrm{kw}$, working width, depth of tillage, height of building ridge, top width, bottom width are $2300 \mathrm{~mm}, 130 \sim 180 \mathrm{~mm}, 300 \mathrm{~mm}, 300 \mathrm{~mm}, 650 \mathrm{~mm}$,respectively.

The machine can complete tillage, setting soil, shaping, pressing, polishing and the surface appearance of building ridge is regular, strong, beautiful, achieving double function truly. Besides, the machine has the advantages of reasonable structure, high efficiency, low fuel consumption, good quality jobs, labor substitution, low operating costs and good economic returns and so on, which is in accordance with the current development of the paddy field mechanization development.

\section{Acknowledgements:}

Foundation item: Project supported by the Jilin provincial Science and Technology Department (20120202) -- Development of rotary and building ridge combined work machine

\section{Reference}

[1] Shihua Cheng, Peisong Hu. Chinese Journal of Rice Science, 2008,22(3):223-224.(In Chinese)

[2] Peizhong Feng. Journal of Jiangsu Institute of Technology[J].1985(4):46. (In Chinese)

[3] Baihe Liu . Farm Machinery . 2011,661(1A):76. (In Chinese)

[4] Daolin Zhang, Peisong Diao, Weichun Zhang. Machinery For Cereals, Oil And Food Processing, 1998,257(3):26-28. (In Chinese)

[5] Zhenjun Guan. Agricultural Science and Technology and Equipment,2011(10): 20-22. (In Chinese)

[6] Bingqi Bao, Longzhe An, Fengying Hu. Journal of Agricultural Mechanization Research. $2002,3: 23-25$. (In Chinese)

[7] Xiuhai Han, Lei Yu, Zhanqiang Xing. Agriculture Science \&Technology and Equipment, 2013,232(10):40-41turn to 44. (In Chinese)

[8] Zhensheng Han. Journal of Agricultural Mechanization Research. 2013,35(6):45-47. (In Chinese)

[9] Jinfeng Wang, Jinwu Wang, Yanjun Kong, Chengliang Zhang, et al. Transactions of the Chinese Society of Agricultural Engineering. 2013,29(6): 28-33. (In Chinese)

[10] Chinese Academy of Agricultural Mechanization Sciences . Agricultural Machinery Design Manual [ M ] . Beijing:China Agricultural Science and Technology Press,2007. (In Chinese)

\section{Author in brief:}

Liping Zhao, Associate Professor, mainly engaged in Mechanization of Agriculture. E-mail: 245042057@qq.com 